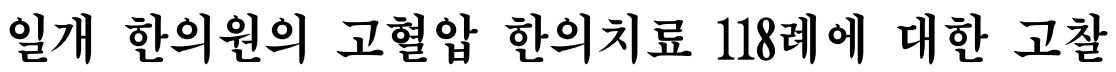

\author{
정용욱, 이기향, 강자연, 정민정 ${ }^{3}$, 김홍준, 장인수 ${ }^{2}$ \\ ${ }^{1}$ 제가한의원, ${ }^{2}$ 우석대학교 한의과대학 한방내과학교실 \\ ${ }^{3}$ 우석대학교 한의과대학 소아과학교실, ${ }^{4}$ 우석대학교 한의과대학 방제학교실
}

\section{Hypertension Treatment: A 118-Case Series in a Korean Medicine Clinic}

\author{
Yong-wook Jeong ${ }^{1}$, Gi-hyang Lee ${ }^{2}$, Ja-yeon Kang ${ }^{2}$, Min-jeong Jeong ${ }^{3}$, Hong-jun Kim², In-soo Jang ${ }^{2}$ \\ ${ }^{1}$ Jega Medical Clinic of Korean Medicine \\ ${ }^{2}$ Dept. of Internal Medicine, College of Korean Medicine, Woo-Suk University \\ ${ }^{3}$ Dept. of Pediatrics, College of Korean Medicine, Woo-Suk University \\ ${ }^{4}$ Dept. of Prescription, College of Korean Medicine, Woo-Suk University
}

\begin{abstract}
Objectives: The aim of this study was to report a 118-case series demonstrating the treatment of hypertension in a Korean medicine clinic and to evaluate the effect of Korean medicine.

Materials \& Methods: From 2006 to 2018, patients who visited a Korean medicine clinic for hypertension were investigated by studying changes in blood pressure before and after treatment with herbal medicine, acupuncture, and Uwhangchungsim-won. The average treatment period was 81.6 days.

Results: After treatment with Korean medicine, the mean systolic blood pressure (SBP) and diastolic blood pressure (DBP) of all patients decreased significantly ( $\mathrm{p}<0.001$ ). The SBP decreased from $148.9 \pm 10.3$ to $133.8 \pm 13.9$, and the DBP decreased from $91.3 \pm 7.5$ to $82.5 \pm 9.0$. After treatment with acupuncture or Uwhangchungsim-won, the patient showed decreased blood pressure but the differences were not statistically significant when compared with the non-treated group.

Conclusions: This study shows the real situation of hypertension treatment in Korean medicine and indicates that Korean medicine could be one of the primary treatment for hypertension. However, this study had limitations, such as variations in the treatment periods, the frequency of acupuncture treatments, and the type of antihypertensive drugs. For further evaluation of the effectiveness of treatment for hypertension using Korean medicine, a well-designed study should be undertaken.
\end{abstract}

Key words: hypertension, herbal medicines, Korean medicine, traditional medicine, before after study

\section{I. 서 론}

고혈압은 만성 순환기계 질환 중 발생빈도가 가

· 투고일: 2018.09.03, 심사일: 2018.09.27, 게재확정일: 2018.10.08

· 교신저자: 장인수 전북 전주시 완산구 중화산동 2-5 우석대부속한방병원

TEL: 063-220-8608 FAX: 063-220-8616

E-mail:mackayj@naver.com

- 제 1 저자는 정용욱, 이기향 2 인이며, 두 저자는 논문에 제 1 저 자로서 동일한 기여도를 가지고 있습니다.
장 높은 질환으로 최근에는 그 발생빈도가 증가하고 있는 추세이다. 또한 고혈압은 무증상으로 침묵의 살인자라고 불리지만 중풍, 심부전, 관상동맥질환 등 치명적인 합병증을 유발할 수 있기 때문에 보 다 적극적인 환자관리와 치료가 요구되고 있다.

고혈압 치료 및 관리를 위해 약물요법과 비 약 물요법이 사용되고 있으며, 고혈압 치료를 위해 연 1 회 이상 의료기관을 방문하는 사람은 890 만명 수 준이며 꾸준히 항고혈압제를 처방 받는 사람은 570 
만명 ${ }^{2}$ 이다. 그러나 약물요법에 대한 부작용, 순응도 에 따른 효과 차이 ${ }^{3}$ 등의 한계점을 보이고 있어 그 대안으로 비 약물요법에 대한 관심도가 점차 높아 지고 있다 ${ }^{4}$

한의학에서도 고혈압 조절에 관한 임상 연구가 점차 늘어나고 있고, 항고혈압제 단독투여와 한약 의 병용투여 시 혈압강하에 대한 체계적 고찰 연 구가 진행되었다 ${ }^{5-7}$. 또한 2016년부터 고혈압 한의 임상진료지침 개발이 이루어지고 있다. 2016년도에 진행된 고혈압 한의진료 실태조사 결과에 따르면, 1 차 진료 기반의 국내 한의원에서도 고혈압 진료 를 위한 기반을 갖추고 있는 것으로 확인 되었으 며 점차 고혈압에 대한 한의사들의 관심이 높아지 고 있는 것으로 사료된다.

이에 본 연구는 실제 혈압치료를 목적으로 한의 원에 내원한 환자를 대상으로, 고혈압에 대한 한약, 침 등 한의학적 치료의 효과를 비교 분석하였다.

\section{II. 연구대상 및 방법}

\section{1. 연구 대상}

2006년 4월부터 2018년 7월까지 창원 제가한의 원에 고혈압 치료를 위해 내원한 환자 118 명 대상 한의치료의 결과를 정리하였다.

\section{2. 연구 방법}

1) 한의치료

한약치료는 동의보감 처방을 기본으로 하였으 며, 임상 한의사가 가감한 임상처방을 주로 사용하 였다. 본 연구에서 주로 加味順氣導痰湯을 위주로 환자의 변증에 따라 八味地黃湯, 滋源地黃湯, 消疸

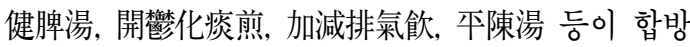
되어 사용되었다(1일 2첩, 1첩당 $80 \mathrm{~g}$ 기준 사용).

변증은 1987년 출판된 채인식의 《한방임상학-변 증시치 $\gg^{9}$ 에 따라, 肝火熾盛型, 陰虛陽立型, 痰濕壅 盛型, 肝風內動型, 陰陽兩虛型, 血虛肝旺型, 氣虛痰 多型 등을 활용하였다.
침치료 역시 각각의 변증에 따라 肝鬱化火(太衝 陽輔 風池 太䈯), 痰濕中阻(風池 豊隆 足三里太 衝), 陰虛陽立(風池 曲池 內關 三陰交 太知) 등을 선별하여 사용하나, 일반적으로 임상 시는 개개인 의 전신증상에 맞는 침구 처방을 구성한다. 침구치 료는 최소 1 주일에 2 회를 받기를 요구하였다.

치료와 더불어 식이조절, 유산소 운동 및 근력운 동을 겸하도록 교육하였다.

2) 평가방법

치료 전후의 측정된 혈압을 비교하여 평가하였 다. 혈압 측정은 한의원에 내원하였을 때 약 10 분 이상 휴식을 취한 후 BP-203RPE II (VP-1000)을 이용하여 1,2 차 측정 후 2 차 측정치를 기록하였다. 치료 기간은 초진 내원 후 1 개월 단위로 검진하며 예후를 파악하였다.

3) 자료수집

창원 제가한의원에 내원한 환자 기준으로 약 10 년간 치료 전후의 혈압, 복용한 한약 종류, 기간, 우황청심원 복용량, 침 치료 횟수 등을 기록하였다. 2018년 8월 자료를 제공받아, 우석대 부속 한방병 원 한방내과에서 자료를 분석하였다.

4) 통계처리

수집된 자료는 window용 IBM SPSS로 치료 전 후 혈압에 대하여 paired t-test를 실시하였고, 처치 에 따른 군간 혈압비교에 대하여 independent t-test 를 실시하였다. 모든 통계는 평균과 표준편차(mean \pm standard deviation)로 나타내었으며 검정결과 P-value 가 0.05 미만인 경우 유의한 것으로 보았다.

\section{III. 연구 결과}

\section{1. 일반적 특성}

대상자의 성별은 남자 64 명, 여자 54 명이었으며, 연령별로 20대 3명, 30대 13명, 40대 31명, 50대 50 명, 60 대 이상 21 명이었으며 평균 나이 51세이다. 각 군의 성별, 나이의 평균은 1 기 고혈압에 해당되는 군은 남자 52명, 여자 39명, 평균 나이 51.9세, 2기 
고혈압에 해당되는 군은 남자 12 명, 여자 15 명, 평 균 나이 49 세였다(Table 1). 총 치료기간은 한약 복용 일수로 보았으며, 각각 치료기간은 1 기 고혈 압은 86.4일, 2기 고혈압은 65.6 일이었다.

Table 1. Characteristics of the Subjects

\begin{tabular}{ccc} 
Characteristics & Stage 1 & Stage 2 \\
\hline Age (yrs) & $51.9 \pm 11.2$ & $19.0 \pm 9.9$ \\
Male (N) & 52 & 12 \\
Female (N) & 39 & 15 \\
Treatment period (days) & 86.4 & 65.6 \\
\hline N : the number of person & &
\end{tabular}

\section{2. 한약치료}

한약 복용 기간은 30 일 42 명, 60 일 33 명, 90 일 18 명, 120 일 10명, 150 일 6 명, 180 일 이상 9 명으로 평균 81.6 일이었다.

한약은 加味順氣導痰湯을 기본방으로 합방한 경 우가 103명으로 가장 많았다. 변증에 따라 消疸健 脾湯 36 명, 滋源地黃湯 28 명, 八味地黃湯 17 명 등 중복합방하여 사용하였다.

\section{3. 기타 치료}

한약 치료와 같은 기간으로 우황청심원을 병용 한 환자 56 명, 복용 중 한의사의 판단에 따라 복용 중단한 환자는 38 명, 비복용한 환자는 24 명이었다.

침 치료는 0회 14명, 1-9회 31명, 10-19회 28명, 20-49회 32명, 50-79회 8명, 80회 이상 5명이었다.

항고혈압제를 복용하지 않고 한의치료만 받은 환자 87 명, 항고혈압제 함께 복용한 환자 18 명, 치 료 도중 항고혈압제를 중단한 환자는 13 명이다.

\section{4. 치료 전후의 혈압 비교}

전체 118 명의 치료 전후의 평균 수축기혈압(Systolic Blood Pressure, SBP), 평균 이완기혈압(Diastolic Blood Pressure, $\mathrm{DBP})$ 은 통계적으로 유의한 감소 를 나타냈다(각각 $\mathrm{p}<0.001$ ), 각 군의 변화를 살펴보 면, 1 기 고혈압의 경우 평균 수축기혈압이 $144.8 \pm 7.1$
에서 $131.7 \pm 12.7(p=0.03)$, 이완기혈압이 $89.0 \pm 5.9$ 에서 $81.3 \pm 8.9(\mathrm{p}=0.01)$ 로 감소했고, 2 기 고혈압의 경우 수축기혈압이 $162.7 \pm 7.0$ 에서 $140.9 \pm 15.7(p=0.02)$, 이 완기혈압 $99.2 \pm 7.0$ 에서 $86.8 \pm 8.3((\mathrm{p}=0.01)$ 로 감소했 다(Table 2, Fig. 1).

Table 2. The Change of the Blood Pressure

\begin{tabular}{ccccc} 
& & Total & Stage 1 & Stage 2 \\
\hline \multirow{4}{*}{ SBP } & Before & $148.9 \pm 10.3$ & $144.8 \pm 7.1$ & $162.7 \pm 7.0$ \\
& After & $133.8 \pm 13.9$ & $131.7 \pm 12.7$ & $140.9 \pm 15.7$ \\
& p-value & $\langle 0.001$ & $\langle 0.05$ & $<0.05$ \\
\hline \multirow{4}{*}{ DBP } & Before & $91.3 \pm 7.5$ & $89.0 \pm 5.9$ & $99.2 \pm 7.0$ \\
& After & $82.5 \pm 9.0$ & $81.3 \pm 8.9$ & $86.8 \pm 8.3$ \\
& p-value & $\langle 0.001$ & $\langle 0.05$ & $<0.05$ \\
\hline
\end{tabular}

Mean \pm Standard Deviation

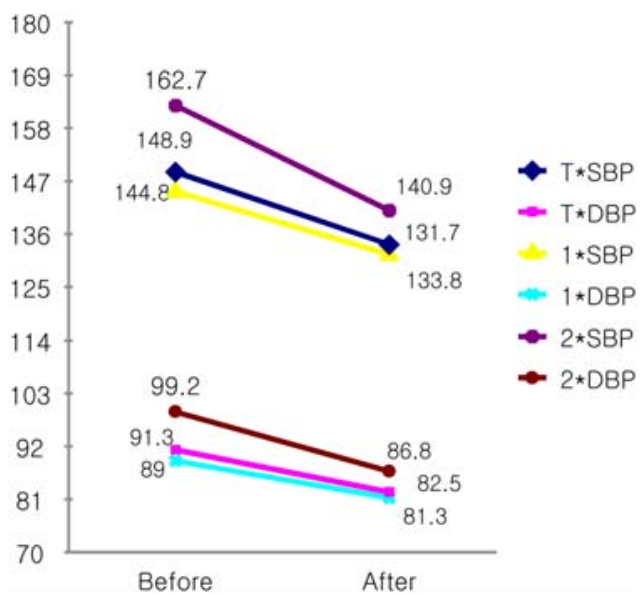

Fig. 1. The change of the blood pressure.

$\mathrm{T}^{*}:$ total, $1^{*}:$ stage $1,2^{*}:$ stage 2

\section{5. 우황청심원 병용에 따른 치료효과}

우황청심원을 복용한 56 명의 환자와 복용하지 않은 24 명의 환자의 $\mathrm{SBP}$ 변화량은 각각 $-14.1 \pm 13.5$, $-15.2 \pm 9.9$ (p>0.5)이었으며, DBP 변화량은 각각 $-8.4 \pm 8.5$, $-8.7 \pm 7.5(\mathrm{p}>0.5)$ 이었다. 혈압감소에 있어서 통계적 으로 유의한 차이를 보이진 못했다. 그러나 우황청 심원을 복용한 환자는 고혈압이 오래 진행되었거 
나, 두통 현훈 마목 등의 증상이 있었으며 복용 후 에는 주관적 증상이 감소함을 확인할 수 있었다.

\section{6. 침치료 병용에 따른 치료효과}

침치료와 $\mathrm{SBP}$ 변화량, $\mathrm{DBP}$ 변화량에 대한 상 관관계는 적은 것으로 확인되었다(각각 상관계수 0.197, 0.171).

\section{7. 항고혈압제 병용에 따른 치료효과}

항고혈압제를 병용한 환자는 18 명, 복용하지 않 고 한의치료만 받은 환자는 87 명이었다. $\mathrm{SBP}$ 의 변 화량은 병용치료군 $-14.2 \pm 16.7$, 한방단독치료군 $-17.4 \pm 11.0$ $(\mathrm{p}=0.30), \mathrm{DBP}$ 의 변화량은 병용치료군 $-8.7 \pm 7.9$, 한방단독치료군 $-10.4 \pm 7.3(\mathrm{p}=0.37)$ 로 확인되었다. 한방단독치료군에서 혈압이 조금 더 감소한 것으 로 보이나 통계적 유의는 없었다.

\section{IV. 고찰 및 결론}

JNC 7지침(The seventh report of the Joint National Committee on Prevention, Detection, Evaluation, and Treatment of High Blood Pressure)에 따르면 $140 \mathrm{mmHg} / 90 \mathrm{mmHg}$ 이상인 경우를 고혈압으로 분류한다.

2016년 보건복지부 국민건강영양조사 결과, 고혈 압 유병률은 만 30세 이상 수축기혈압 $140 \mathrm{mmHg}$ 이상이거나 이완기혈압이 $90 \mathrm{mmHg}$ 이상 또는 고 혈압약물을 복용한 분율로 전체 $29.1 \%$, 남자 $35.0 \%$, 여자 $22.9 \%$ 이다. 고혈압 환자에서 수축기 혈압을 $10 \mathrm{mmHg}$ 낮출 경우 주요 심혈관 사건 발생, 관상 동맥질환, 뇌졸중, 심부전, 총 사망률을 10-30\% 유 의하게 낮출 수 있다 ${ }^{10}$.

본 연구에서는 고혈압에 대한 한의치료의 효과 를 알아보기 위하여 한의원에 내원한 환자의 치료 결과를 분석하였다. 분석 대상 환자는 항고혈압제 복용여부에 관계없이 JNC-7 기준에 따라 1기고혈 압에 해당하는 $\mathrm{SBP} / \mathrm{DBP}(\mathrm{mmHg})$ 140-159/90-99,
2기고혈압에 해당하는 $\mathrm{SBP} / \mathrm{DBP}(\mathrm{mmHg}) 160$ 이 상/100 이상인 총 118 명이었다. 전체 환자의 수축 기혈압은 $148.9 \pm 10.3$ 에서 $133.8 \pm 13.9(\mathrm{p}=0.000)$, 이완 기혈압은 $91.3 \pm 7.5$ 에서 $82.5 \pm 9.0(\mathrm{p}=0.000)$ 으로 감소 함을 보아 한약치료가 혈압강하에 효과가 있는 것 으로 보인다.

고혈압 진단 표준으로 肝陽上立, 痰濕內盛, 病血 內停, 肝腎陰虛, 腎陽虛衰 등의 변증을 사용하고, 天麻鉤藤飲, 牛夏白术天麻湯, 血府逐瘀湯, 六味地黃 丸 등의 처방을 적용할 수 있다. 최근 국내에서 고 혈압에 대한 한약처방의 효과에 대한 논문들이 발 표되고 있는 가운데, 천마구등음 ${ }^{5} 11,12$ 을 항고혈압제 와 병용 치료 시 항고혈압제 단독치료에 비해 우 수한 혈압강하 효과를 보였으며, 이수제 ${ }^{13}$ 또는 오 령산 $^{6}$ 병용 투여 시에도 항고혈압제 단독투여에 비 하여 부가적인 강압효과를 보였다. 기국지황환과 항고혈압제 병용치료 시 항고혈압제 단독치료보다 효과가 우수함을 보여주었다. 본 한의원에서는 더 확장된 肝火熾盛, 陰虛陽六, 痰濕雍盛, 肝風內動, 陰陽兩虛, 血虛肝旺, 氣虛痰多 등의 변증을 활용하 였는데, 주로 사용한 처방은 醫學入門에 수록되어 있는 順氣導痰湯의 가감방이다. 이는 理氣化痰의 효능을 가진 처방으로 牛夏 $8 \mathrm{~g}$, 南星 陳皮 枳實 赤获荅 鳥藥川芎白芷 白䡒蛀 黃連 黃芩 각 $4 \mathrm{~g}$, 桔梗 竹茹 遠志 甘草 각 $2 \mathrm{~g}$, 生瞢 3편으로 이루어 져있다. 한의학의 특성 상 환자 개개인에게 하나의 처방이 아닌 합방으로 이루어진 처방으로 사용되 었기에 한약처방에 대한 분석이 정확하게 이루어 질 수는 없었지만, 한약 단독 처방 또는 항고혈압 제와의 병용투여가 혈압 강하에 도움이 됨은 명확 히 확인 할 수 있었다.

牛黃淸心元은 1107년경 太平惠民和劑局方에 최 초로 수록된 이래로 중풍, 고혈압, 동맥경화증, 자 율신경실조증, 정신불안증, 히스테리, 불면 등에 활 용되며, 중풍의 구급약으로서 뿐만 아니라 심뇌혈 관계 및 신경계 질환에 널리 응용되고 있다 ${ }^{14}$. 본 연구에서도 많은 수의 환자에게 우황청심원을 병 
용하게 하였고, 그 결과를 분석했을 때 우황청심원 복용군과 비복용군의 혈압이 모두 감소함을 확인 하였으나. 두 군의 차이는 통계적으로 유의하지 않 았으나 두통, 현훈 등 주관적 증상은 감소한 것으 로 확인되었다. 또한, 우황청심원이 혈관확장작용, 혈압강하작용 및 이뇨작용 등이 있음을 보고한 논 문 $^{15}$ 이 있고, 선천성 고혈압 쥐의 혈압과 심박동수 감소작용이 있는 것으로 보고되어 우황청심원의 임상적 효능을 실험적으로 검증한 바 있다 ${ }^{16}$. 다만, 우황청심원이 정상인의 혈압과 맥박에 미치는 영 향은 유의성이 없는 것으로 보고된 연구도 있기에 ${ }^{17}$, 초기 혈압 강하 효과와 낮아진 혈압을 유지시키는 효과를 따로 비교하는 연구가 차후 필요할 것으로 생각된다.

침치료는 고혈압에 대해 잠재적인 효과가 있는 대안적인 치료로 제시되고 있고, 고혈압에 대한 침 의 치료효과를 증명하는 연구가 꾸준히 이루어지 고 있다 ${ }^{18}$. 본 연구에서도 병용 치료로 침치료가 이 루어졌으나, 환자마다 침 치료 빈도가 차이가 있어 아쉬운 부분이다. 본 연구에서는 침 치료가 혈압강 하 효과 사이에서 상관관계가 적은 것으로 확인 되었으나 침 치료가 고혈압 및 고혈압 전단계에서 효과를 보였고(가 있고) ${ }^{19,20}$, 고혈압에 대한 침요법 이 약물요법에 대한 보조적인 치료로 효과가 있다 고 보고된 체계적 문헌고찰 연구 ${ }^{21}$ 를 참고한다면, 고혈압 치료에 보조적으로 사용가능할 것으로 보 인다.

고혈압은 예방 및 관리가 반드시 필요한 질환이 다. 대부분의 고혈압 치료는 양방병원에서 이루어 지고 있으나, 만성질환의 관리 측면에 있어 한방병 원, 한의원에서의 치료 역시 접근성이 높아지고 있 다. 한약 및 침구 병용 치료 등 한의 치료 및 주기 적인 혈압측정, 식사습관, 운동, 금연, 절주 등과 같 은 비약물치료 또는 생활요법 등으로 혈압관리를 꾸준히 유지하여 1년 이상 혈압이 목표혈압 이하 로 잘 조절된다면 항고혈압제의 감량 ${ }^{22}$, 항고혈압제 의 효과를 최대화하며 부작용을 줄임과 동시에 일
차 진료에서의 한의학 역할이 커질 것으로 기대된다.

본 논문은 환자들의 실제 복용하는 항고혈압제 의 분류, 한약 복용 횟수 및 침구치료 빈도 등이 다양하여 일관적으로 비교할 수 없는 아쉬움이 있 으나 실제 임상현장에서 행해지는 고혈압 진료를 확인할 수 있음에 의의가 있다.

\section{감사의 글}

본 연구는 한국보건산업진흥원을 통해 보건복지 부 「한의약선도기술개발사업 의 재정 지원을 받아 수행된 연구임(HB16C0023).

\section{참고문헌}

1. Association of Korean Medicine Professors for Cardiovascular and Neurological Medicine. Cardiovascular and neurological medicine in Korean medicine I. Seoul: Uri medical books; 2016, p. 196-8.

2. Cho MC. Korea Hypertension Fact Sheet 2018. The Korean Society of Hypertension. 2018, p. 7.

3. Elliott WJ. What factors contribute to the inadequate control of elevated blood pressure? $J$ Clin Hypertens (Greenwich) 2008;10(1 Suppl 1) :20-6.

4. Powers M, Jalowiec A. Profile of the well-Controlled, well-Adjusted hypertensive patients. Nurs Res 1987:36(2):106-10.

5. Kang KW, Kang JY, Kim HJ, Sun SH, Jang IS. The Effect of Cheonmagudeung-eum for Hypertension: A Systematic Review and Meta-analysis. The Journal of Internal Korean Medicine 2018:39(1) :22-43.

6. Lee HY, Kang KW, Lee E, Lee SH, Han CH, Jang IS. A Systematic Review on Antihypertensive 
Effects of Oryeong-san. The Journal of Korean Oriental Internal Medicine 2013:34(3):289-97.

7. Han IS, Shin JH, Cho YY, Park HM, Yang CS, Jeong MJ, at el. Qu-Ji-Du-Huang-Wan for Essential Hypertension : Systemic Review and Meta-analysis. Korean Journal of Oriental Physiology \& Pathology 2017:31(2):118-25.

8. Kang JY, Kang KW, Jeong MJ, Kim HJ, Jang IS. A Study on Survey of Hypertension Treatment in Korean Medicine. The Journal of Korean Oriental Internal Medicine 2016:37(6):1022-9.

9. Chae IS. Clinical Science of Oriental Medicine Pattern Identification. Seoul: Daesungmunhwa; 1987.

10. Ettehad D, Emdin CA, Kiran A, Anderson SG, Callender T, Emberson J, et al. Blood pressure lowering for prevention of cardiovascular disease and death: a systematic review and meta-analysis. Lancet 2016:387(10022):957-67.

11. Zhou QY, Ma KQ, Guo YX, Dai XF, Chen XL. Meta-analysis of Tianma Gouteng Decoction Combined with Angiotensin-converting Enzyme Inhibitors for Treating Primary Hypertension. Chinese Journal of Experimental Traditional Medical Formulae 2015:21(4):206-12.

12. Zhou QY, Ma KQ, Guo YX, Chen J, Chen XL, $\mathrm{Xu} Q$, et al. Therapeutic Effect of Tianma Gouteng Decoction Combined with Captopril in Treatment of Primary Hypertension: A Systematic Review and Meta-analysis. Journal of Anhui Traditional Chinese Medical College 2013:32(4) :12-7.

13. Kang JY, Kang KW, Jeong MJ, Kim HJ, Jang IS. The Effect of Korean Herbal Medicine with Function of Inducing Diuresis for Hypertension : Systematic Review and Meta Analysis of Randomized Controled Trials. The Journal of
Korean Oriental Internal Medicine 2017:38(4):433-42.

14. Kim LD, Yun SP, Lee SH, Kim EJ, Na BJ, at el. Effects of Uwhangchungsim-won(Niuhuangqingxin -yuan) on Systemic Blood Pressure, Pulse, Rate, Cerebral Blood Flow, and Cerebrovascular Reactivity in Humans. The Journal of Korean Oriental Internal Medicine 2004;25(3):440-50.

15. Hong ND, Kim NJ, Kim KS. Effect of Woohwangchungsim -Won on the Cardiovascular System Studies on the Efficacy of Combined Preparation of Crude Drugs. The Korean Society of Pharmacognosy $1988 ; 18(4): 241-8$.

16. Cho TS, Lee SM, Kim ND, Huh IH, Ann HS, Kwon KI, at el. Pharmacological Actions of New Wonbang Woohwangchungsimwon Pill on Cardiovascular System. Yakhak Hoeji 1999;43(2) :237-50.

17. Hwang JW, Kim CH, Min IK, Kim YJ, Leem JT, Na BJ, at el. A Comparative Study about Cerebrovascular Reactivity from a Single Medication and Continuous Medication on Healthy Subjects. $J$ Korean Oriental Medicine 2009;30(1):95-108.

18. Lee H, Kim SY, Park J, Kim YJ, Lee H, Park HJ. Acupuncture for lowering blood pressure: systematic review and meta-analysis. American Journal of Hypertension 2009;22(1):122-8.

19. Liu Y, Park JE, Shin KM, Lee MH, Jung HJ, Kim AR, et al. Acupuncture lowers blood pressure in mild hypertension patients: a randomized, controlled, assessor-blinded pilot trial. Complement Ther Med 2015;23(5):658-65.

20. Yin C, Seo B, Park HJ, Cho M, Jung W, Choue $\mathrm{R}$, et al. Acupuncture, a promising adjunctive therapy for essential hypertension: a double-blind, randomized, controlled trial. Neurol Res 2007; 29 Suppl:S98-103.

21. Zhao XF, Hu HT, Li JS, Shang HC, Zheng 
HZ, Niu JF, et al. Is Acupuncture Effective for Hypertension? A Systematic Review and Meta-Analysis. PLoS One 2015;10(7) :e0127019. 22. Kim CH, Park SH, Choi BS, Jang WH, Choi SH,
Kim JH, et al. Evidence-based Guideline for Hypertension in Primary Care. Seoul: Korean Academy of Medical Sciences; 2016, p. 45-51. 